\title{
Modelo de Thom para o zoneamento bioclimático de Mato Grosso do Sul ${ }^{1}$
}

\author{
Amaury de Souza², Hamilton Germano Pavão², Giancarlo \\ Lastoria $^{3}$, Sandra Garcia Gabas ${ }^{3}$, Guilherme Henrique Cavazzana ${ }^{4}$ \\ \& Antonio Conceição Paranhos Filho ${ }^{3}$
}

\begin{abstract}
RESUMO
O objetivo deste trabalho foi avaliar as condições de clima do Mato Grosso do Sul, por meio do índice de temperatura e umidade (ITU), e apresentar o zoneamento bioclimático relacionado ao conforto térmico. Os valores de ITU foram estimados a partir de dados de temperatura e umidade relativa do ar para o período de 1979 a 2008. Quatro intervalos de ITU foram usados para classificar o desempenho humano (ITU<74: conforto; $74 \leq$ ITU $<79$ : quente; $79 \leq$ ITU $<84$ : muito quente, e ITU>84: extremamente quente), e dois intervalos para classificar a produção animal ( $79 \leq T U<84$ : perigoso e ITU $>84$ : emergência). Considerandose que o clima predominante tem uma alternância de duas estações ao longo do ano: verão quente e úmido e inverno seco com temperaturas mais amenas, os resultados mostraram maior risco de desconforto térmico no período de outubro a abril, comparado ao período entre maio e setembro. O período mais crítico ocorreu entre dezembro e março. Observa-se que valores de ITU entre 77,9 e 83,9 , humanos e animais podem sofrer algum grau de estresse térmico durante as horas mais quentes do dia, afetando ambos negativamente.
\end{abstract}

Palavras-chave: Ambiente térmico, zoneamento biclimático, temperatura, umidade relativa.

\begin{abstract}
The objective of this study was to evaluate the climate conditions of Mato Grosso do Sul, using the index of temperature and humidity (ITU), and present the bioclimatic mapping relating to thermal comfort. The ITU values were estimated from data of temperature and relative humidity for the period 1979 to 2008. Four intervals of ITU were used to classify human performance (ITU $<74$ : comfort; $74 \leq \mathrm{ITU}<79$ : hot: $79 \leq \mathrm{ITU}<84$ : very hot, and $\mathrm{ITU}>84$ : extremely hot), and two intervals to classify the Livestock $(79 \leq \mathrm{ITU}<84$ : dangerous and ITU $>84$ : emergency). We conclude that the prevailing mood is one of two alternating seasons throughout the year: hot and humid summer and dry winter with warmer temperatures, the results showed a higher risk of thermal discomfort during the period from October to April, compared to the period between May and September. The most critical period occurred between December and March. Although it was observed that with ITU values between 77.9 and 83.9 , humans and animals can suffer some degree of heat stress during the hottest hours of the day, negatively affecting both.
\end{abstract}

Key words: Thermal environment, bioclimatic mapping, temperature, relative humidity.

1 Artículo recibido el 7 de febrero de 2010 y aceptado el 12 de mayo de 2010.

2 Depto de Física, Universidade Federal de Mato Grosso do Sul (Brasil). E-mail: amaury@nin.ufms.br; pavão@nin.ufms.br

3 Depto de Hidráulica e Transportes, Universidade
Federal de Mato Grosso do Sul (Brasil). E-mail: lastoria@nin.ufms.br; sandragabas@nin.ufms.br; toniparanhos@gmail.com

4 Centro de Ciências Exatas e Tecnologia, Universidade Federal de Mato Grosso do Sul (Brasil). E-mail: gui_cavazzana@yahoo.com.br 
Quando se pretende discutir o conforto térmico urbano, estamos nos referindo ao clima urbano que, segundo (Monteiro, 1976), se define como "um sistema que abrange o clima de um dado espaço terrestre e sua urbanização. São um mesoclima que está incluído no macroclima e que sofrem, na proximidade do solo, influências microclimáticas derivadas dos espaços urbanos".

Segundo Fanger (1970), o conforto térmico é uma condição da mente que expressa à satisfação do indivíduo com o ambiente térmico. Nesse sentido, o conforto térmico pode ser analisado como sendo as trocas térmicas que dependem de vários fatores, sejam eles ambientais e/ou pessoais, comandados por processos físicos.

O clima é um dos principais fatores que afetam a produção animal, sendo estratégico o seu conhecimento para o projeto de instalações e de sistemas de arrefecimento e para o manejo dos animais. Assim, para que os animais possam exprimir todo o seu potencial produtivo, torna-se necessário considerar a interação entre genética, nutrição, sanidade e ambiente térmico. O ambiente térmico, geralmente, engloba os efeitos da radiação solar, temperatura $\left(\mathrm{t}_{\mathrm{ar}}\right)$, umidade relativa (UR) e velocidade do vento (v) (Falco, 1997; Baêta \& Souza, 1997), sendo a combinação $t_{a r}$ - UR o principal condicionante para conforto térmico.

Por outro lado, enquanto a ambiência animal tem recebido maior atenção por parte dos pesquisadores, poucos estudos têm sido conduzidos com relação à ambiência do trabalhador rural.

Embora seja do conhecimento que altos valores de $\mathrm{t}_{\mathrm{ar}}$ e UR resultam em desconforto térmico, geralmente prejudicial para os seres humanos, muito pouco tem sido feito para amenizá-lo, tendo como conseqüência prejuízo à saúde dos trabalhadores rurais, tendo-se percebido que o rendimento e o risco de acidentes dos trabalhadores estão mais relacionados ao desconforto térmico. Na tentativa de estabelecer critérios para a classificação dos ambientes, foram desenvolvidos diversos índices de conforto térmico que visam a englobar, em um único parâmetro, o efeito conjunto dos elementos meteorológicos e do ambiente construído sobre o indivíduo estudado, homem ou animal. Exemplos de índices térmicos desenvolvidos para animais são: índice de temperatura e umidade - ITU (Thom, 1957), índice de temperatura do globo negro e umidade - ITGU (Buffington et al., 1981), índice de desconforto térmico - IDT (Yanagi Júnior et al., 2001), índice de temperatura, umidade e velocidade do ar - ITUV (Tao \& Xin, 2003). Para humanos, pode-se citar o índice de estresse térmico - SW (Belding \& Hatch, 1955), o índice de bulbo úmido e temperatura do globo - IBUTG (Yaglou \& Minard, 1957; Thom, 1957).

Apesar de existirem índices de conforto térmico mais completo que o ITU, esse tem sido muito utilizado por envolver apenas informações meteorológicas normalmente disponíveis em estações meteorológicas e em bancos de dados obtidos a partir de imagens de satélite.

Assim, para o projeto e manejo de instalações para produção animal e verificação das condições de conforto térmico animal e do trabalhador rural, podem-se utilizar informações advindas de bancos de dados, principalmente meteorológicos. Esses bancos de dados podem ser trabalhados por meio da tecnologia de sistema de informações geográficas (SIG), possibilitando a geração de mapas temáticos, como, por exemplo, o zoneamento bioclimático de uma determinada região, importante para a tomada de decisão com relação à ambiência animal e humana.

Este trabalho teve o objetivo de fazer o zoneamento bioclimático de Mato Grosso do Sul, por meio do índice de temperatura e umidade (ITU).

\section{Material e métodos}

Foi utilizados dados diários, mensais e anuais de precipitação, temperatura média e máxima do ar e umidade relativa do período compreendido entre os anos de 1979 e 2008, das estações meteorológicas de: Campo Grande, lon. $54^{\circ} 37^{\prime} \mathrm{W}$; lat. $20^{\circ} 27^{\prime} \mathrm{S}$, Corumbá, lon. $57^{\circ} 3^{\prime} \mathrm{W}$; lat. $19^{\circ} 05^{\prime} \mathrm{S}$, Coxim, lon. $54^{\circ} 46^{\prime} \mathrm{W}$; lat. $18^{\circ} 3^{\prime} \mathrm{S}$, Dourados, lon. $54^{\circ} 59^{\prime} \mathrm{W}$; lat. $22^{\circ} 14^{\prime} \mathrm{S}$, Ivinhema, lon. $53^{\circ}$ 56' W; lat. 22 19' S, Paranaíba, lon. 51 11'

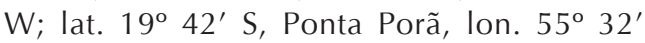
W; lat. $22^{\circ} 32^{\prime} \mathrm{S}$, Três Lagoas, Ion. $51^{\circ} 42^{\prime}$ 
W; lat. $20^{\circ} 47^{\prime} \mathrm{S}$, que permitiram analisar o comportamento das chuvas no decorrer do tempo (Figura $N^{0} 1$ ). As principais atividades econômicas desenvolvidas no estado de Mato Grosso do Sul estão relacionadas à agricultura e à agroindústria, à extração mineral e à produção de cimento. Os principais produtos agrícolas cultivados no estado incluem algodão herbáceo, arroz, cana-de-açúcar, feijão, mandioca, milho, soja e trigo. O rebanho bovino totaliza 19,6 milhões de cabeças, encontrando-se também grande número de suínos, eqüinos, ovinos e galináceos. A atividade mineradora produz um total de 833,8 mil toneladas de ferro; 447,6 mil toneladas de manganês; e 1,1 milhões de toneladas de calcário. No setor industrial, além da mineração e da produção de cimento, a indústria alimentícia também merece destaque.

A partir dos dados diários e mensais de precipitação, foi possível a identificação e análise de variáveis como os totais e médias pluviométricas, bem como sua distribuição sazonal e espacial e períodos secos. Para a identificação dos períodos secos, utilizou-se como metodologia a contagem de períodos superiores há 75 dias sem a ocorrência de precipitações e/ou sem a ocorrência de chuvas significativas (precipitações acima de 2,5 $\mathrm{mm}$, valor inferior à evapotranspiração potencial diária do período).

Na confecção dos balanços hídricos, utilizou-se a metodologia proposta por Thornthwaite \& Mather (1955). O balanço hídrico climatológico (BHC) foi desenvolvido por Thornthwaite \& Mather (1955) para determinar o regime hídrico de um local, sem necessidade de medidas diretas das condições do solo. Para sua elaboração, há necessidade de se definir o armazenamento máximo no solo (CAD - Capacidade de Água Disponível), e de se ter a medida da chuva total, e também a estimativa da evapotranspiração potencial em cada período. Com essas três informações básicas, o BHC permite deduzir a evapotranspiração real, a deficiência ou o excedente

Figura $\mathrm{N}^{\circ} 1$

Localização do Estado de Mato Grosso do Sul e a sua divisão político-geográfica

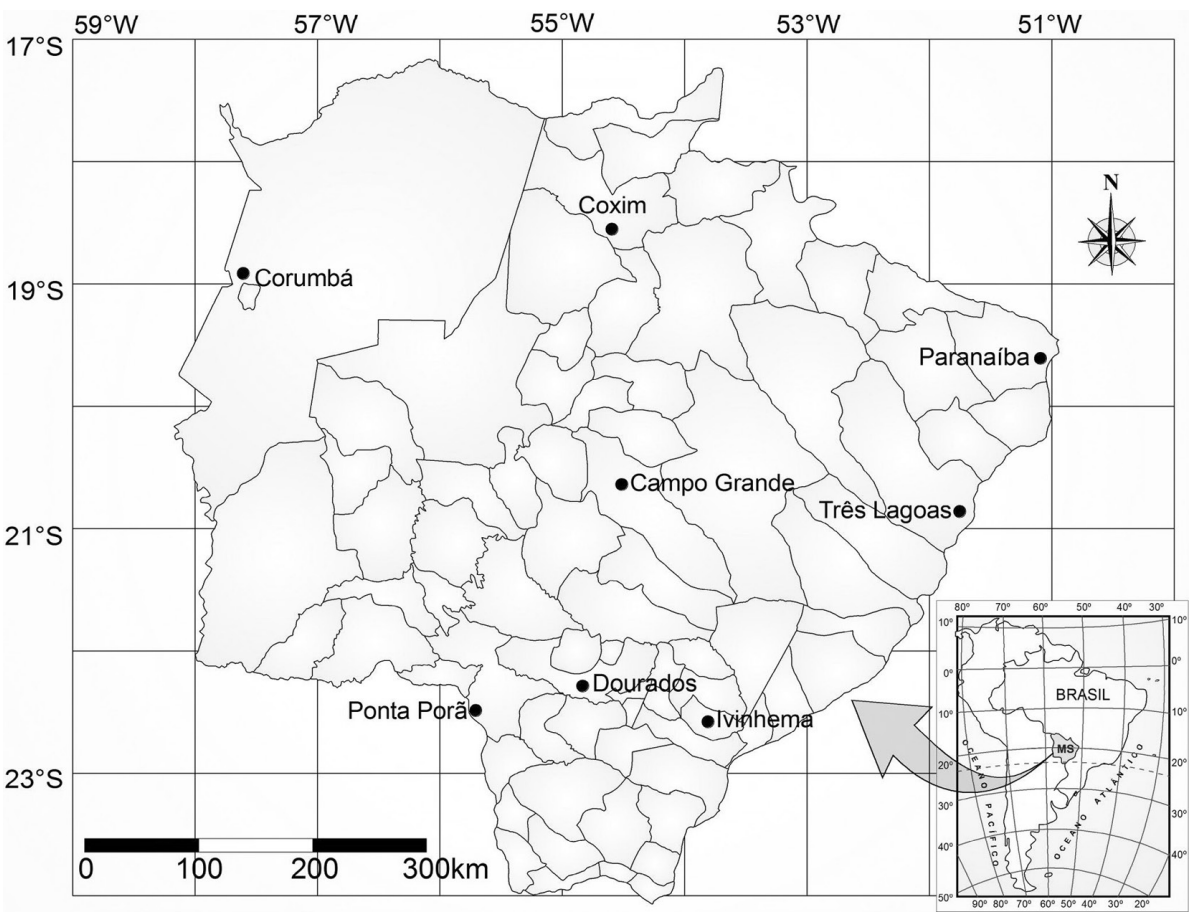

Fonte: GuiaNet, 2004. 
hídrico, e o total de água retida no solo em cada período. Como o solo é um reservatório que dificulta a saída da água à medida que vai secando, nos períodos em que o total de chuvas $(P)$ é menor que a evapotranspiração potencial (ETP), a água retida torna-se uma função dessa demanda potencial $(P-E T P<0)$ e da CAD adotada. Havendo uma seqüência de períodos nessa condição, a água retida no solo será uma função seqüencial dos valores negativos acumulados de P - ETP, ou seja, da perda potencial acumulada (Thornthwaite \& Mather, 1955).

Foi elaborado o mapeamento das zonas térmicas do Mato Grosso do Sul por meio do índice de temperatura e umidade (ITU), desenvolvido por Thom (1957), visando a definir zonas de conforto térmico para pessoas.

$$
\text { ITU }=t_{\mathrm{bs}}+0,36 \mathrm{t}_{\mathrm{po}}+41,5(1)
$$

Em que,

$\mathrm{t}_{\mathrm{bs}}$ - temperatura de bulbo seco $\left({ }^{\circ} \mathrm{C}\right)$, e $t_{\mathrm{po}}$ - temperatura do ponto de orvalho $\left({ }^{\circ} \mathrm{C}\right)$, obtida pela metodologia proposta por $\mathrm{Wi}$ Ihelm (1976).

Com base nos estudos desenvolvidos por Olgyay (1963, 1968), Koenigsberger et al. (1977), Rivero (1986), Lamberts et al. (1997) e dos parâmetros mencionados, foram definidas as seguintes zonas de conforto e desconforto térmico para trabalhadores de granjas:

ITU < 74: conforto térmico adequado;

$74 \leq$ ITU < 79: ambiente quente, no qual se inicia o desconforto térmico, podendo causar problemas de saúde e redução no rendimento do trabalhador rural;

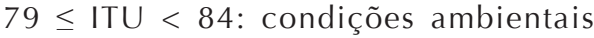
muito quentes, indicando perigo e podendo trazer conseqüências graves à saúde do trabaIhador rural, e

ITU > 84: indica condição extremamente quente, com risco muito grave à saúde do trabalhador rural.

De acordo com Thom (1957), Hahn (1982), Rosemberg et al. (1983), Du Preez et al. (1990), Hubbard et al. (1999), Cabral
(2001) e Huhnke et al. (2001), para aves, bovinos e suínos, os intervalos de ITU considerados são de:

79 < ITU < 84: implica condição de perigo para os animais, indicando aos produtores a necessidade de se tomarem precauções para evitar perdas na produção, e

ITU > 84: indica situação de emergência, sendo necessário que providências urgentes sejam tomadas para evitar a perda do plantel.

Para os animais, não foram feitas classificação com relação às zonas de conforto e início de desconforto, por ser variável entre as espécies. Para aves, os intervalos de ITU são idênticos aos usados para humanos; por outro lado, para bovinos de leite, valores entre 72 e 79 comprometem o desempenho produtivo e reprodutivo.

A estimativa do índice ITU foi determinada de hora em hora para todos os dias, no período mencionado. Para tanto, a determinação dos valores horários $t_{a r}$, ao longo do dia, foi feita a partir de dados de temperatura mínima do ar $\left(\mathrm{t}_{\min }\right)$, temperatura do ar às $9 \mathrm{~h}$ do horário local $\left(t_{9}\right)$, temperatura máxima do ar $\left(\mathrm{t}_{\text {máx }}\right)$ e temperatura do ar às $21 \mathrm{~h}$ do horário local $\left(\mathrm{t}_{21}\right)$, utilizando-se da metodologia proposta por Zolnier (1996). A escolha desse modelo para a estimativa da variação diária da temperatura baseia-se no estudo desenvolvido por Lyra et al. (2003), que mostraram o melhor ajuste obtido por esse modelo, comparado ao proposto por Campbell \& Norman (1998). Os valores horários de UR também foram obtidos por interpolação, de acordo com a metodologia proposta por Zolnier (1996).

Os dados horários de $t_{a r}$ e UR para cada dia dos anos estudados, para cada latitude e longitude, foram usados como entrada em um programa desenvolvido, para os cálculos das $t_{a r}$ e UR horárias médias e máximas. Esses dados foram usados para a determinação das temperaturas do ponto de orvalho ( $\left.\mathrm{t}_{\mathrm{po}}\right)$, permitindo, em seguida, o cálculo do ITU (Thom, 1957) para cada horário, com base na metodologia proposta por Wilhelm (1976).

Para a geração dos mapas temáticos, utilizou-se o aplicativo SPRING-Sistema para Processamento de Informações Georreferenciadas 
(Câmara et al., 1996), e o banco de dados fornecidos pelo INEMET. A partir das informções georreferenciadas de ITU médio e máximo dentro dos intervalos considerados, foram geradas imagens contendo as classes representativas dos valores de ITU cada mês do ano. A finalização dos mapas geraos foi feita por meio do módulo SCARTA do aplicativo SPRING.

\section{Resultados e discussões}

De acordo com Nimer (1979), esta microrregião apresenta certa uniformidade climática no que diz respeito aos mecanismos atmosféricos (principalmente à circulação das massas de ar), o que faz com que a diversificação térmica regional se dê em função de fatores geográficos como o relevo, a latitude e a longitude (continentalidade). O mesmo autor, afirma que "todos os fatores climáticos estáticos, tais como o relevo, agem sobre o clima de determinada região em interação com os sistemas regionais de circulação atmosférica, o que demonstra a importância de conhecer os sistemas de circulação que atuam sobre a região no decorrer do ano para, assim, entender a dinâmica climática da área de estudo.

No que diz respeito à distribuição sazonal e espacial das precipitações, Nimer (1979) afirma ser estas muito simples, graças às características do terreno que não oferece grandes barreiras aos sistemas de circulação atmosférica, que definem o regime pluviométrico da Região Centro-Oeste.

Em razão da pouca significância da topografia sobre a pluviosidade, a altura média alcançada pela precipitação durante o ano sobre o território regional do centro-oeste brasileiro apresenta uma distribuição muito simples: de um núcleo mais chuvoso ao norte de Mato Grosso do Sul, Coxim com 1.492 $\mathrm{mm}$ com decréscimo para $\mathrm{L}$ e $\mathrm{O}$. No extremo O de Mato Grosso do Sul, o regime cai a 1.117 mm, Corumbá, no Pantanal Sul-MatoGrossense, e na região sul onde apresenta os maiores valores de 1.660 mm, Ponta Porã.

Entretanto, essas precipitações não se distribuem igualmente através do ano. Em quase toda região, mais de $70 \%$ do total de chuvas acumuladas durante o ano se precipita de novembro a março, sendo geralmente mais chuvoso o trimestre, novembro-janeiro.
Durante esse trimestre chove em média 45\% a $55 \%$ do total anual. Em contrapartida, o inverno é excessivamente seco. Nessa época do ano as chuvas são muito raras, havendo, em média, geralmente, 4 a 5 dias de ocorrência deste fenômeno por mês, sendo mais raras no setor oeste de Mato Grosso do Sul, onde, pelo menos um mês, não registra sequer 1 dia de chuva. A seca acontece no trimestre de inverno, ou seja, junho-julho-agosto.

Os valores das temperaturas médias mensais e anuais registrados levam ao entendimento de que a variação espacial e sazonal desta variável climática segue as características da região, sendo a altitude e a continentalidade, assim como a ação das massas Tropical Atlântica, Tropical Continental e Polar Atlântica as responsáveis pelas principais variações observadas.

As maiores médias térmicas são observadas entre os meses de outubro a março, que corresponde ao verão no domínio dos climas tropicais no Hemisfério Sul, sendo o mês de outubro o que apresenta as maiores médias, visto que este se caracteriza pela transição entre o período seco e chuvoso. Assim, as mudanças nos padrões de circulação atmosférica, os altos índices de evapotranspiração, as baixas velocidades médias dos ventos e as precipitações incipientes, como a baixa umidade do ar, favorecem a elevação das temperaturas, que indicam o início do verão. Outra análise que pode ser feita a partir das temperaturas médias é que a amplitude térmica observada entre os meses com maiores e menores temperaturas é muito baixa, variando $4,0^{\circ} \mathrm{C}$ em média, entre o mês de junho (menores médias térmicas) e o mês de outubro (mês mais quente).

A distribuição das médias pluviométricas anuais e mensais na região é uniforme no espaço e no tempo, visto que a maior e a menor média total foram aferidas nos municípios, o que leva a crer que apenas fatores topográficos não possuem papel condicionante na distribuição espacial destas variáveis, visto que as condições de circulação atmosférica são praticamente as mesmas para toda a porção do estado de Mato Grosso do Sul.

Em uma escala macro, as principais massas de ar que influenciam a variação e a dis- 
tribuição sazonal das precipitações na região são a Tropical Atlântica e a Polar Atlântica (no inverno) e a Massa Tropical Atlântica (no verão). Assim, em uma escala de abrangência mais localizada, as variações espaciais são de responsabilidade de fatores como a topografia e a continentalidade, bem como pode sofrer a influência da direção predominante das massas de ar.

É possível observar que a média pluviométrica regional é de $1.446 \mathrm{~mm}$, com uma variação na precipitação média anual entre $1.117 \mathrm{~mm}$ (Corumbá) e $1.660 \mathrm{~mm}$ (Ivinhema). No que diz respeito à variação sazonal dos índices de precipitação, observa-se que no decorrer do ano as chuvas seguem a regra geral observada na região dos cerrados, apresentando duas estações bem definidas: um verão quente e chuvoso e um inverno seco, com temperaturas mais amenas.

A estação chuvosa (outubro a março/abril) concentra mais de $85 \%$ das chuvas anuais, sendo que dezembro e janeiro contribuem com mais de $35 \%$ da precipitação anual. Já a estação seca que em alguns anos tem início no mês de abril e se estende até o início de outubro, tem como característica uma redução sensível nos índices pluviométricos sendo que, no trimestre mais seco do ano (junho-agosto), as chuvas representam, em média, menos de $2 \%$ do total anual.

Durante a estação seca é possível observar longos períodos sem ocorrência de chuvas e/ou com chuvas insignificantes, bem abaixo da evapotranspiração (Etp) diária e que não altera a condição de secura do ambiente. Esses períodos, não raro chegam a superar os 100 dias. Durante o período de análise, a quantidade de anos e a média de dias seguidos que ocorreram tais períodos secos prolongados, não são superiores aos 75 dias consecutivos.

Também se observa que as médias de dias, nos anos em que ocorreram longos períodos secos acima do limite mínimo da pesquisa foram de 105 dias, e a média de dias sem chuvas significativas (menor que 2,5 $\mathrm{mm}$ ) é de 110 dias e que praticamente metade dos anos apresenta um longo período sem chuvas superando os 75 dias ininterruptos. Tal período coincide com a época do ano da estação seca, sendo mais comum sua ocorrência nos meses de junho, julho e agosto podendo chegar até em meados de setembro.

O déficit hídrico pronunciado entre os meses de maio e outubro e a probabilidade de ocorrência de déficits nos meses de fevereiro, março e abril (em função da ocorrência de veranicos) indica a necessidade do uso de técnicas de irrigação, ao menos em regime emergencial ou suplementar (durante a estação chuvosa), condição necessária para garantir o pleno desenvolvimento das culturas e a manutenção dos índices de produtividade. Na pecuária, é preciso considerar, também, a necessidade de construção de silos e outras formas alternativas de suplementação alimen$\operatorname{tar}$ (capineiras) ou até mesmo o confinamento do rebanho durante a estação seca, visto que, em alguns anos o déficit hídrico acentuado, resseca por completo as pastagens.

Em média, a deficiência hídrica (DEF) possui uma variação local entre $15 \mathrm{~mm}$ (Campo Grande) e $331 \mathrm{~mm}$ (Corumbá). Entre maio a setembro é verificado o maior índice mensal de DEF. Nesse período a probabilidade de ocorrer DEF no solo é superior a $80 \%$ dos meses, sendo que em algumas localidades nos meses de junho, julho e agosto a probabilidade de haver DEF chega aos 100\% dos meses. A observação de DEF nos meses de janeiro e fevereiro deve-se a ocorrência de veranicos (intervalos de dias consecutivos sem chuvas durante a estação chuvosa). Já nos meses de novembro e dezembro, sua ocorrência está ligada a atrasos nos início do período chuvoso. Os maiores excedentes hídricos (EXC) médios mensais distribuem-se entre os meses de dezembro e março. Nesse período a probabilidade de verificação de EXC chega a superar os $80 \%$ dos meses, sendo que em dezembro e janeiro este índice é superior a $90 \%$ dos anos analisados. Os excedentes médios variam espacialmente de acordo com as características climáticas de cada município, embora as variações sazonais sejam semelhantes, com exceção de Corumbá que apresenta EXC zero. Durante a estação seca, especialmente no trimestre junho-setembro, não foi verificado a ocorrência de EXC, pois os períodos de chuvas são muito reduzidos ou nem mesmo são registrados sua ocorrência. É interessante observar que, mesmo o período chuvoso iniciando em outubro, em mais de $50 \%$ dos anos 
estudados este mês apresentou deficiências hídricas, mesmo com médias pluviométricas consideráveis. Por esse motivo, afirma-se que o mês de outubro, na área em questão, corresponde a uma transição entre o período seco e o período chuvoso do ponto de vista hidrológico. A mesma conclusão pode ser estendida ao mês de abril, pois em determinados anos há uma antecipação da estação seca, como pode ser o contrário, com um prolongamento da estação chuvosa até o respectivo mês.

Após o processamento dos dados climáticos, determinação do ITU e geração dos mapas temáticos observam-se, de janeiro a julho, a tendência de resfriamento da região, sendo posteriormente seguida por aquecimento até dezembro, mostrando a influência das estações do ano sobre o clima regional (Quadro $\mathrm{N}^{\circ} 1$ e Figuras $N^{\circ} 2$ e No 3 ).

Os valores médios de ITU méd. e máx (indicado entre parênteses) para as estações do ano, verão, outono, inverno e primavera, são de $75,9(84,3) ; 69,6(78,3) ; 70,9(80,7)$ e 74,7
$(81,9)$, respectivamente. Assim, com base nos valores de ITU méd e ITU máx, verifica-se que, todas as estações do ano apresentam certo grau de estresse térmico, tanto para os animais quanto para os trabalhadores rurais (Quadro $N^{\circ} 1$ ). Entretanto, quando analisados os valores máximos durante o ano, observase que situações de estresse térmico podem ocorrer durante todos os meses do ano. Como se verifica pelos valores de Vmáx para ITU máx (Quadro $N^{\circ} 1$ ), a condição de perigo para os animais pode ser observada para todos os meses do ano. Durante o período de desconforto térmico, no qual o valor de ITU máx para animais é alcançado, verifica-se a necessidade, por parte dos produtores, de tomarem precauções para evitar perdas na produção, tais como, manutenção e/ou instalação de sistemas de ventilação e/ou resfriamento evaporativo.

Nas Figuras $\mathrm{N}^{\circ} 2$ e $\mathrm{N}^{\circ} 3$, ilustra-se a variação do ITU méd e do ITU máx ao longo do ano. Os meses de maio a setembro caracterizam-se pelos menores riscos de desconforto

Quadro No 1

Estatística descritiva para o índice médio de temperatura e umidade (ITU méd.) mensal e índice máximo de temperatura e umidade (ITU max.) mensal

\begin{tabular}{|l|l|l|l|l|l|l|l|l|}
\hline \multirow{2}{*}{ Mês } & \multicolumn{5}{|c|}{ ITU méd. } & \multicolumn{4}{c|}{ ITU max. } \\
\cline { 2 - 8 } & $\mathrm{X}$ & $\mathrm{S}$ & $\mathrm{V} \min$ & $\mathrm{V} \max$ & $\mathrm{X}$ & $\mathrm{S}$ & $\mathrm{V}$ min & V max \\
\hline Jan & 74 & 1,1 & 71,9 & 76 & 83,2 & 2,5 & 80,1 & 86,9 \\
Fev & 79,3 & 2,7 & 74,5 & 83,6 & 89,1 & 3,1 & 83,3 & 94 \\
Mar & 75,6 & 2 & 71,2 & 78,5 & 84,2 & 3 & 75,4 & 88,1 \\
Abr & 74,1 & 5 & 60,2 & 78,4 & 82,7 & 6,5 & 65,1 & 88,5 \\
Mai & 71,3 & 3,9 & 60,6 & 75,4 & 80,4 & 4,8 & 64,7 & 84,9 \\
Jun & 70,5 & 2,5 & 63,2 & 74,6 & 79,2 & 3,5 & 68,9 & 82,7 \\
Jul & 66,5 & 0,2 & 55 & 74,5 & 75,6 & 1,4 & 61,6 & 83,4 \\
Ag & 71 & 6 & 58,1 & 81,5 & 81,8 & 5,5 & 64,9 & 89,4 \\
Set & 69,2 & 6,2 & 55,5 & 78,2 & 78,8 & 7,6 & 56,8 & 88,1 \\
Out & 74,6 & 2,9 & 69,9 & 80,9 & 82,9 & 4,1 & 73,3 & 89,4 \\
Nov & 74,4 & 2,6 & 67,8 & 77,9 & 82 & 3,7 & 72,6 & 87,5 \\
Dez & 75,4 & 2 & 70,7 & 79 & 83,1 & 2,7 & 76 & 87 \\
\hline
\end{tabular}

X: média mensal de ITU; S: desvio-padrão, Vmín: valor mínimo observado; Vmáx: valor máximo observado. Fonte: Elaboração própia. 
térmico devido aos menores valores de temperatura e umidade relativa do ar, indicando ser o período de menor risco à produção animal e o período no qual os trabalhadores rurais podem obter maiores rendimentos no desenvolvimento de atividades de campo, além de reduzir os riscos de acidentes causados devido ao desconforto térmico.

Conforme especificado anteriormente, não foram feitas classificações para o ambiente animal no intervalo de transição entre conforto e desconforto, por haver diferenças entre as espécies.
Os problemas relacionados aos altos valores de ITU são mais bem caracterizados por meio do ITUmáx, conforme Figura $N^{\circ} 3$, em que se verificou que as mesorregiões que apresentaram problemas relacionados aos altos valores de ITU foram Campo Grande, Corumbá, Ivinhema, Ponta Porã, Três Lagoas.

Com relação ao rendimento dos trabalhadores rurais ao longo do ano, verifica-se que, em parte da região do Mato Grosso do Sul, os trabalhadores rurais podem estar sujeitos a início de desconforto térmico $(74 \leq \mathrm{ITU}<$ 79), e, em outras, o ambiente térmico é ca-

Figura $\mathrm{N}^{\circ} 2$

Distribuição espacial e temporal do índice médio de temperatura e umidade mensal (ITU méd), para o Estado de Mato Grosso do Sul (1981 e 2008)
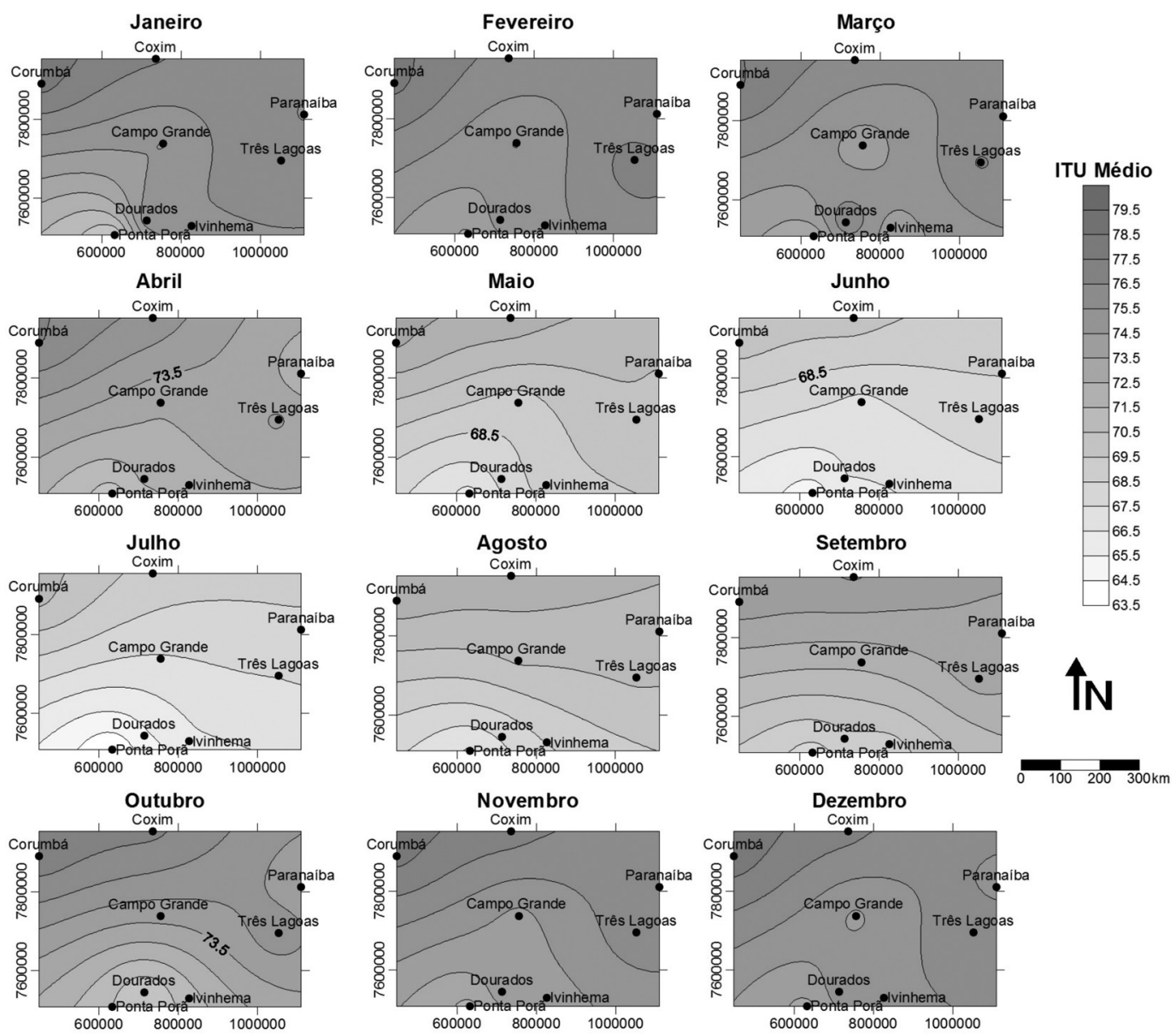

Fonte: Elaboração própia. No está em JPEG 
racterizado como de condições ambientais muito quentes, o que pode trazer danos à saúde dos trabalhadores rurais (Figura №3).

Entre novembro e abril, verificou-se a ocorrência de valores de ITU que caracterizam condições de desconforto térmico em diferentes níveis, tanto para humanos quanto para animais, sendo os meses mais críticos de dezembro a março.

\section{Considerações finais}

A análise dos dados de ITU com base no zoneamento bioclimático mostrou que o pe- ríodo entre maio e setembro se caracterizou pelos menores riscos de desconforto térmico animal e trabalhadores rurais. Porém, podem ser observados níveis diferenciados de desconforto térmico devido às altas temperaturas e umidades relativas durante certas horas do dia para todas as mesorregiões ao longo do ano, sendo que as mesorregiões com maiores problemas decorrentes do calor são Campo Grande, Corumbá, Ivinhema, Ponta Porã, Três Lagoas.

Pode-se afirmar que a metodologia de Thom (1957) mostrou-se satisfatória quanto à aplicação dos dados e seus resultados, pois

Figura $\mathrm{N}^{0} 3$

Distribuição espacial e temporal do índice máximo de temperatura e umidade mensal (ITUmáx), para o estado de Mato Grosso do Sul, no período compreendido entre os anos de 1981 e 2008
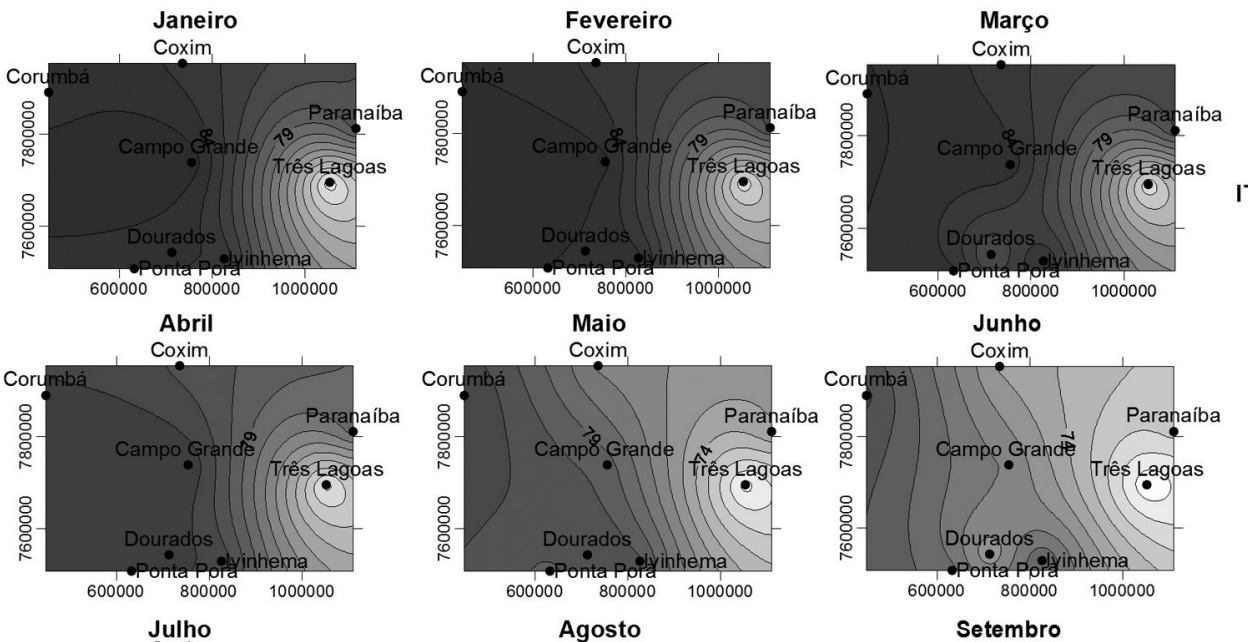

ITU Máximo
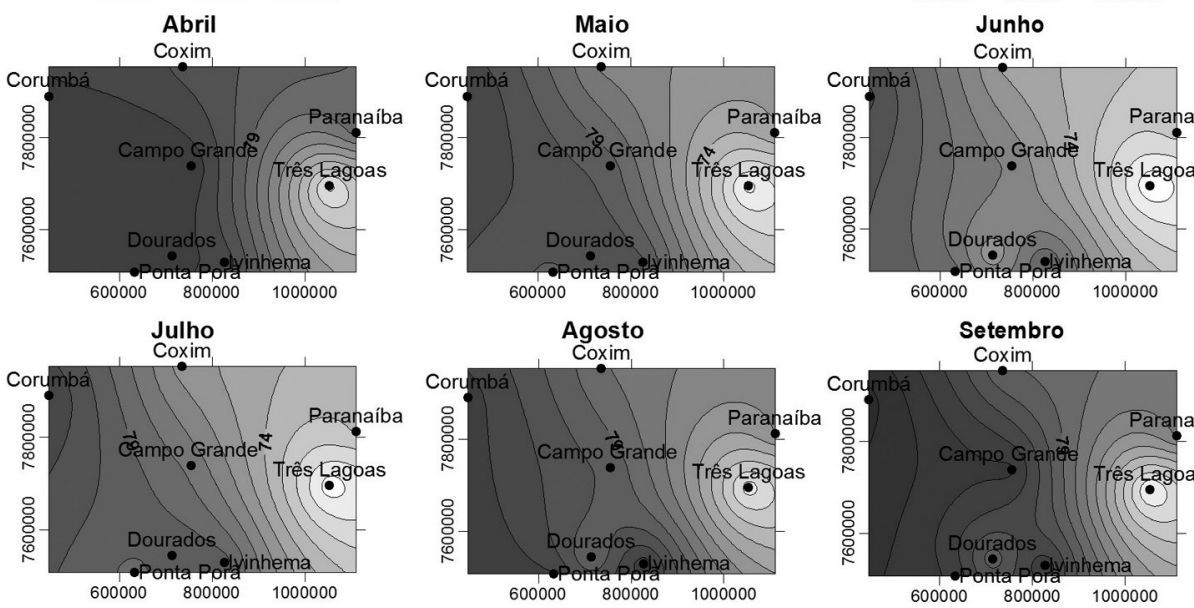

$600000 \quad 800000 \quad 1000000$
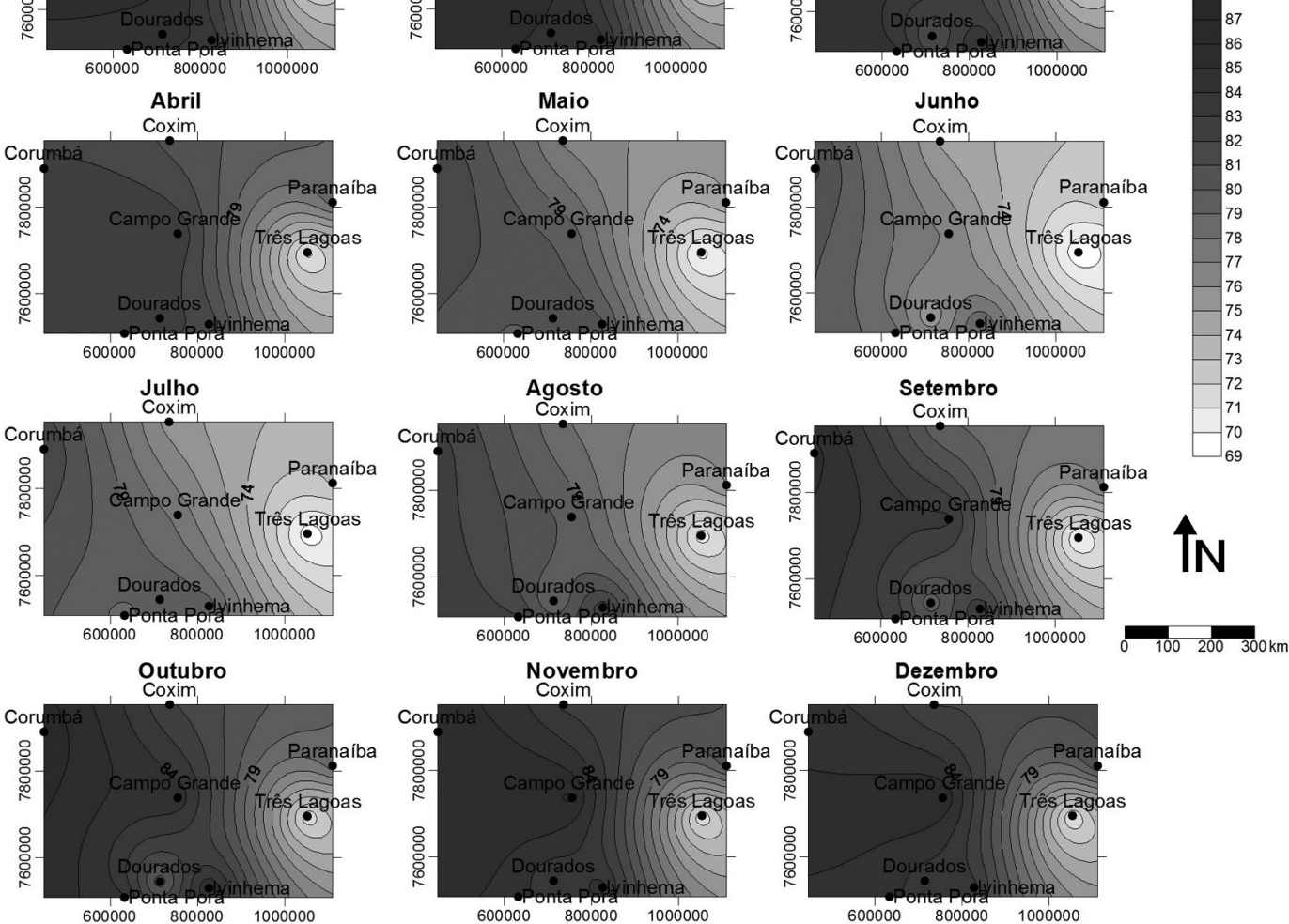

Fonte: Elaboração própia. 
expressam a realidade climática da região estudada. Nesse sentido, a necessidade de dados climatológicos com maior representatividade no que tange ao tamanho da série utilizada, para promover uma investigação mais aprofundada.

\section{Referências bibliográficas}

BAÊTA, F. \& SOUZA, C. Ambiência em edificações rurais: conforto térmico animal. Viçosa: Editora UFV, 1997.

BELDING, H. \& HATCH, T. Index for evaluating heat stress in terms of resulting physiological strains. Heating, piping and air conditioning. Journal Section, 1955, v. 27, p. 129-36.

BUFFINGTON, D. et al. Black globehumidity index (BGHI) as comfort equation for dairy cows. Transactions of the ASAE, 1981, vol. 24, No 3, p. 711-14.

CABRAL, J. Mapeamento da região Sudeste do Brasil usando o ITU, para o gado de leite. Dissertação Mestrado em Meteorologia Agrícola. Viçosa: Faculdade de Engenharia Agricola, Universidade Federal de Viçosa, Brasil, 2001.

CÁMARA, G.; SOUZA, R.C.M.; FREITAS, U.M. \& GARRIDO, J. SPRING. Integrating remote sensing and gis by object-oriented data modelling. Computers \& Graphics, 1996, vol. 20, No 3, p. 395-403.

CAMPBELL, G. \& NORMAN, J. An introduction to environmental biophysics. New York: Springer, 1998.

DU PREEZ， J.; GIESECKE，W.; HATTINGH, P. Heat stress in dairy cattle and other livestock under Southern African conditions. I. Temperature-humidity index mean values during the four main seasons. Onderstepoort Journal Veterinary Research, 1990, vol. 57, No 1, p. 77-87.

FALCO, J. Bioclimatologia animal. Lavras: UFLA, 1997.

FANGER, P. Thermal confort. New York: McGraw-Hill Book Company, 1970.
GUIANET. Mapa do Mato Grosso do Sul. Campo Grande: GuiaNet, 2010. Disponible en Internet: http://www.guianet.com.br/ms/ mapams.gif

HAHN, G. Compensatory performance in livestock: influences on environmental criteria. In: AMERICAN SOCIETY OF AGRICULTURAL ENGINEERS (ASAE). International Livestock Environment Symposium 2. Hitchin: Herts, Gt. Britain, 1982, p. 285-294.

HUBBARD, K.; STOOKSBURY, D.; HAHN, G. \& MADER, T. A climatological perspective on feedlot cattle performance and morality related to the temperature-humidity index. Journal Production Agriculture, 1999, vol. $12, \mathrm{~N}^{\circ} 4$, p. 650-653.

HUHNKE, R.; MCCOWAN, L.; MEREZ, G.; HARP. S. \& PAYTON, M. Determining the frequency and duration of elevated temperaturehumidity index. In: ASAE. Annual International Meeting. California: ASAE, 2001, p. 1-12.

KOENIGSBERG, O.; INGERSOLL, T.; MAYHEW, A. \& SZOKOLAY, S. Viviendas y edificios en zonas cálidas y tropicales. Madrid: Paraninfo, 1977.

LAMBERTS, R.; DUTRA, L.; PEREIRA, F. Eficiência energética na arquitetura. São Paulo: PW Editores, 1997.

LYRA, G.; CABRAL, S.; JÚNIOR, J.; SANTOS, S.; SILVA, W. Modelos empíricos para estimativa da variação diária da temperatura do ar em Piracicaba - SP. In: SOCIEDADE BRASILEIRA DE AGROMETEOROLOGÍA. Anais Congresso Brasileiro de Agrometeorologia 13. Santa Maria: SBA, 2003, p. 727-728.

MONTEIRO, C. Teoria e clima urbano. São Paulo: Instituto de Geografia da USP, Série Teses e Monografias N²5, 1976.

NIMER, E. Climatologia do Brasil. Rio de Janeiro: IBGE, 1979.

OLGYAY, V. Clima y arquitectura en Colombia. Cali: Carvajal, 1968.

OLGYAY, V. Design with climatebioclimate approach to architectural regionalism. Princeton: University Press, 1963. 
RIVERO, R. Arquitetura e clima: acondicionamento térmico natural. Porto Alegre: D. C. Luzzatto Editores, 1986.

ROSENBERG, N.; BLAD, B. \& VERMA, S. Microclimate, the biological environment. New York: Wiley-Interscience Publication, 1983.

TAO, X. \& XIN, H. Acute synergistic effects of air temperature, humidity, and velocity on homeostasis of market-size broilers. Transactions of the ASAE, 2003, vol. $46, N^{\circ} 2$, p. 491-497,

THOM, E. The discomfort index. Weatherwise, 1959, vol.12, № 1, p. 57-60.

THORNTHWAITE, C. W. \& MATNER, J. R. The water balance. Publications in Climatology. New Jersey: Drexel Institute of Technology, 1955.
YAGLOU, C. \& MINARD, D. Control of heat casualties at military training centers. Archives of Industrial Health, 1957, vol. 16, p. 302-305.

YÁNAGI JUNIOR, T.; XIN, H. \& GATES, R. Thermal discomfort index for laving hens. In: ASAE. 94th ASAE Annual International Meeting. Sacramento: ASAE, 2001, p. 1-16.

WILHELM, L. Numerical calculation of psychrometric properties in SI units. Transactions of the ASAE, 1976, vol. 19, $\mathrm{N}^{\circ}$ 2, p. 318-325.

ZOLNIER, S. Avaliação de modelos para estimativa dos valores médios horários do índice de temperatura e umidade. Engenharia na Agricultura, 1996, vol. 5, № 16, p. 1-17. 